\title{
Águas Maravilhosas (Macaé, RJ): do rio ao lixão na memória de uma catadora de lixo
}

\section{Águas Maravilhosas (Macaé, RJ): the River that Became a Garbage Dump and the Point of View of a Gargabe Picker}

\author{
Rafael Nogueira COSTA* \\ Giuliana Franco LEAL ${ }^{* *}$ \\ Celso Sánchez PEREIRA***
}

\begin{abstract}
RESUMO
Este trabalho tem como objetivo analisar o processo histórico da descaracterização de um rio e sua transformação em depósito de lixo a partir da memória, narrativas e percepções de uma ex-catadora sobre as mudanças ambientais ocorridas no local. Pretende-se, ainda, descrever alguns aspectos do município de Macaé (RJ), o cotidiano dos catadores, assim como o processo de ativação e desativação deste depósito. O estudo foi feito a partir da exibição de filme e de entrevistas exploratórias a respeito da história e da vida no lixão, realizadas com a ex-catadora, que nos revela seu ponto de vista, sui generis, construído a partir da sua condição e de suas percepções acerca das mudanças ambientais experimentadas pela informante. Espera-se que o resgate histórico da descaracterização de um ambiente, com relevâncias ambientais, históricas e sociais, relatado por uma pessoa que viu e vivenciou todas as etapas desta ausência de planejamentos e estudos técnicos, possa contribuir para futuras intervenções neste local.
\end{abstract}

Palavras-chave: catadora de lixo; narrativas; memória e imagem; transformações ambientais.

\begin{abstract}
This study aims to analyze the historical process of adulteration of a river and its transformation into a garbage dump based on the memory, narratives and insights of an ex-garbage picker about environmental changes on the site. It also aims to describe some aspects of Macaé city, the daily lives of garbage workers, as well as the process of activation and deactivation
\end{abstract}

\footnotetext{
" Mestre em Engenharia Ambiental (IFF) e doutorando em Meio Ambiente (UERJ). Professor da Universidade Federal do Rio de Janeiro (UFRJ-Campus Macaé). E-mail: rcosta@macae.ufrj.br

"* Doutora em Sociologia (UNICAMP). Professora da Universidade Federal do Rio de Janeiro (UFRJ-Campus Macaé). E-mail: giulianafrancoleal@yahoo.com.br

*** Doutor em Educação (PUC-Rio). Professor da Universidade Federal do Estado do Rio de Janeiro (UNIRIO). E-mail: celso.sanchez@hotmail.com
} 
of this deposit. The study was done based on the film exhibition and exploratory interviews about the history and life of the landfill, conducted with an ex-garbage picker who reveals his view, sui generis, built from their condition and its perceptions of environmental changes experienced by the informant. It is expected that the historic rescue of the mischaracterization of an environment, with environmental, historical and social relevance, reported by a person who has seen and experienced all the stages of this lack of planning and technical studies, may contribute to future interventions to this site.

Keywords: garbage picker; narratives; memory and image; environmental transformations.

\section{Introdução}

Este artigo tem a intenção de compreender, a partir da narrativa de uma ex-catadora e moradora de um lixão de Macaé, o processo histórico da descaracterização de um rio e sua transformação em depósito de lixo. Pretendemos, ainda, descrever alguns aspectos do município de Macaé, o cotidiano dos catadores, assim como o processo de ativação e desativação deste depósito, o maior da cidade estudada. Buscaremos apresentar os resultados da narrativa de uma moradora e a sua percepção sobre as questões ambientais, relacionadas principalmente com o risco decorrente da exposição a contaminantes.

O presente estudo foi realizado durante os meses de janeiro de 2011 a junho de 2012. A moradora foi uma das primeiras a chegar ao local, que funcionou como depósito de lixo da cidade de Macaé, Norte Fluminense, a cerca de $200 \mathrm{~km}$ da cidade do Rio de Janeiro, durante o período de 1977 a 2000. A entrevistada presenciou todo o ciclo de funcionamento do lixão, da implantação à desativação e, atualmente, continua morando na localidade. Com a finalidade de buscarmos uma maior compreensão do histórico de ocupação do local e do cotidiano dos catadores na época em Macaé, realizamos a exibição, para a nossa entrevistada, das imagens do lixão de São Gonçalo, presentes no filme Boca de lixo, dirigido pelo cineasta Eduardo Coutinho em 1992.

A passagem de Bakhtin é o ponto de partida de nossas reflexões e interpretações neste texto:

Não existe a primeira nem a última palavra, e não há limites para o contexto dialógico (este se estende ao passado sem limites e ao futuro sem limites). Nem os sentidos do passado, isto é, nascidos no diálogo dos sé- culos passados, podem jamais ser estáveis (concluídos, acabados de uma vez por todas): eles sempre irão mudar (renovando-se) no processo de desenvolvimento subsequente, futuro do diálogo. Em qualquer momento do desenvolvimento do diálogo existem massas imensas e ilimitadas de sentidos esquecidos, mas em determinados momentos do sucessivo desenvolvimento do diálogo, sem seu curso, tais sentidos serão relembrados e reviverão em forma renovada (em novo contexto). Não existe nada absolutamente morto: cada sentido terá sua festa de renovação (BAKHTIN, 2003, p. 410).

Para Wertsch (2010, p. 123), a razão para invocar as ideias de Bakhtin está relacionada à sua visão intelectual, oferecendo um modelo teórico poderoso sobre o qual pode ocorrer colaboração interdisciplinar. Além disso, como analisa o autor, as afirmações bakhtinianas são consistentes com as análises de como as enunciações podem ser construídas ou de como elas podem ser respostas abreviadas a uma questão.

Buscamos estimular a comunicação com a entrevistada, a partir das evidências reais, apresentadas nas imagens de outro espaço utilizado como depósito de lixo. Neste sentido, a visualização das imagens, assim como a convivência entre antigos companheiros, nutre a comunicação entre visões de mundo que se interpenetram, em um movimento de reconstrução do passado (FROCHTENGARTEN, 2005, p. 367). Tal como definido por Maurice Halbwachs (1990, p. 26), o indivíduo carrega em si a lembrança, mas está sempre interagindo com a sociedade, seus grupos e instituições. É no âmbito dessas relações que construímos as nossas lembranças.

Neste sentido, o trabalho a partir das narrativas deve ter em mente a advertência de Benjamin, para quem: 
Ela [a narrativa] mergulha a coisa na vida do narrador para em seguida retirá-la dele. Assim se imprime na narrativa a marca do narrador [...] Os narradores gostam de começar sua história com uma descrição das circunstâncias em que foram informados dos fatos que vão contar [...] Assim, seus vestígios estão presentes de muitas maneiras nas coisas narradas, seja na qualidade de quem as viveu, seja na qualidade de quem as relata (BENJAMIN, 1994, p. 205).

Outro aspecto relevante ao se trabalhar com as narrativas a partir de memórias é o que nos alerta Bosi, ao notar as diferenças de temporalidade na própria pessoa que narra sua memória:

Por mais nítida que nos pareça a lembrança de um fato antigo, ela não é a mesma imagem que experimentamos na infância, porque nós não somos os mesmos de então e porque nossa percepção alterou-se e, com ela, nossas ideias, nossos juízos de realidade e de valor. $\mathrm{O}$ simples fato de lembrar o passado, no presente, exclui a identidade entre as imagens de um e de outro, e propõe a sua diferença em termos de ponto de vista (BOSI, 1979, p. 55).

Compreender as formas de depósito e a composição do lixo, apesar de ser imprevisível tanto na sua qualidade como na sua quantidade, pode ser de extrema importância para solucionar possíveis problemas atuais de contaminação dos catadores e do ambiente no qual foi instalado o lixão.

Neste artigo, apresentamos inicialmente as características do local onde foi feita a pesquisa. Após esboçarmos os procedimentos metodológicos empregados, analisamos o depoimento da moradora e ex-catadora do lixão que constituiu o centro de nossa análise, especialmente a partir da recepção do documentário sobre o lixão de São Gonçalo, e traçamos considerações sobre as consequências socioambientais dos lixões. Todas as etapas da investigação convergem para a compreensão das condições de vida e de trabalho e do cotidiano dos catadores do lixão de Macaé.

\section{Procedimentos metodológicos}

Com o objetivo de investigar como era o lixão, no qual hoje se encontra a comunidade das Águas Maravilhosas, a partir das memórias e reminiscências recolhidas nas narrativas, foram realizadas oito entrevistas exploratórias a respeito da história e da vida no lixão com moradores. Entretanto, a entrevista que mais focamos neste artigo é a da moradora mais antiga, a única que assistiu ao documentário e opinou sobre ele. Localizamos a informante-chave ${ }^{1}$ por indicação dos moradores do bairro. Para localizá-la, foi utilizado o método conhecido como "bola de neve" (BERNARD, 1988). A entrevistada em questão começou a morar na localidade para ficar mais próxima do rio que utilizava frequentemente para pescar, antes de a área virar lixão. Devido à utilização do local para depósito de lixo, a mesma deixou de pescar para viver da coleta de material reciclável, além de alimento.

Foi exibida uma edição curta do filme Boca de lixo e, a partir das narrativas de uma catadora, recolheram-se suas impressões e memórias. Além disso, o estudo pretendeu conhecer o cotidiano e as condições de trabalho dos catadores de Macaé. Buscamos, como um dos meios para avançar nesse entendimento, a comparação entre o lixão da cidade de Macaé e o lixão de São Gonçalo (RJ).

A pesquisa foi realizada em seis etapas: 1) revisão bibliográfica sobre o lixão e seus problemas; 2) pesquisa em jornais locais; 3 ) depoimentos de outros moradores de Águas Maravilhosas; 4) edição do filme Boca de Lixo, reduzindo o material para três minutos; 5) exibição do documentário editado para a ex-catadora do lixão de Macaé; e 6) análises dos indicadores, previamente identificados no vídeo pelo discurso da entrevistada.

\section{O local de estudo, Macaé (RJ)}

O município de Macaé (RJ) desde o século XIX se destacou pela agricultura em seu extenso interior serrano e nas baixadas, além de ser o porto da economia açucareira centrada em Campos, com a qual se ligava por meio de

\footnotetext{
${ }^{1}$ Apesar de a pesquisa focalizar prioritariamente a narrativa de uma ex-catadora e uma das mais antigas moradoras da comunidade, seus instrumentos captaram também outros aspectos relacionados com as questões de contaminação ambiental, conflitos sociais e políticas públicas locais.
} 
canais e de uma ferrovia (SEVÁ, 2012, p. 8). A cidade entrou para o cenário econômico mundial no fim da década de 1970, quando foi descoberto o petróleo na região da Bacia de Campos (correspondendo atualmente a $80 \%$ da extração nacional). A escolha da cidade de Macaé, para ser a base exploratória das jazidas petrolíferas em alto-mar, foi responsável por uma gigantesca transformação nessa região. Fruto da poderosa indústria de extração de petróleo, essas transformações começaram com a chegada de diversas empresas (nacionais e estrangeiras), atraindo milhares de pessoas em busca de oportunidades. Assim, estão sendo registradas, nas últimas décadas, as maiores taxas de crescimento urbano do Brasil. Entretanto, a população carente vem se concentrando preferencialmente em áreas impróprias, como o estuário, nas proximidades dos rios e nas restingas do município.

A cidade apresenta uma população estimada de 206.728 habitantes, segundo o Censo Demográfico de 2010 (IBGE, 2010), e continua crescendo rapidamente, consolidando um fenômeno demográfico iniciado na década de 1980. Outrossim, a chegada de diversas empresas, o aumento populacional e a ausência de políticas públicas satisfatórias favoreceram o surgimento de alguns efeitos negativos, tais como: i) pressão sobre os recursos naturais; ii) degradação dos ecossistemas; iii) aumento dos índices de criminalidade; e iv) carência nos sistemas públicos de ensino, saúde e coleta/destinação de resíduos, entre outros. Alguns estudos apontam que as rendas do petróleo não produziram impactos significativos nos indicadores sociais de saúde e de educação dos municípios beneficiados. Mas, de forma surpreendente, geraram efeitos negativos sobre seus setores formais de trabalho (POSTALI; NISHIJIMA, 2011; CORREAA et al., 2011).

A problemática socioambiental em Macaé surgiu em um contexto de deterioração ambiental aliado às atividades de catação nos lixões. O lixão de Macaé funcionou entre os anos de 1977 e 2000, acompanhando esse crescimento populacional, sendo o principal destino dos resíduos sólidos da cidade durante essa época.

\section{Águas Maravilhosas, o lixão de Macaé}

Águas Maravilhosas, o local que virou depósito de lixo, apresenta no nome o principal aspecto da contradição inerente a esses ambientes. Nesse sentido, a sua localização, próxima a um córrego com ligação direta com o principal rio da cidade, reforça o problema. Nos últimos anos do século XX, a área era utilizada pelos macaenses para banho, pesca e lazer durante os dias mais quentes. Essa área próxima ao córrego foi descaracterizada duas vezes: a primeira, pela transformação em depósito de lixo, e a segunda, após a desativação seguida por serviço de terraplanagem sem nenhum tipo de remediação - e ocupação de dezenas de famílias, apoiada por um movimento de trabalhadores sem-terra e pelo prefeito da época, conforme relato dos próprios moradores.

A deposição de lixões próximos aos córregos ocorre por decisões precipitadas, realizadas com total ausência de planejamento e estudos técnicos do espaço físico, possibilitando o aparecimento de problemas clássicos, como contaminação do lençol freático. A história do lixão de Macaé é um exemplo de irresponsabilidade administrativa e medidas semelhantes vêm sendo realizadas por inúmeras prefeituras. Assim, não é um problema local, pois ocorreu em diversas regiões, conforme apresentado em outros trabalhos (SHIRAIWA, 2002; SILVA et al., 2002; GIATTI et al., 2010).

A desativação do lixão ocorreu quando os governantes construíram, nas proximidades, uma rodovia de ligação centro-norte (Linha Azul) para atender ao crescimento da cidade. Após a construção desse eixo viário, o lixão foi desativado, aterrado e a área começou a ser invadida. Neste espaço encontram-se aproximadamente 147 domicílios e 485 habitantes vivendo em uma região precariamente servida de infraestrutura, com ausência de água, esgoto e luz (Plano Local de Habitação de Interesse Social, realizado pela Secretaria de Habitação da Prefeitura de Macaé e aprovado em audiência pública em 2010). Essa ausência de infraestrutura pública está relacionada com o fato de a comunidade estar edificada sobre um vazadouro não remediado e atualmente sob a intervenção do Ministério Público Estadual desde 2010. O local ainda apresenta o canal que deu origem ao nome 
da comunidade, Águas Maravilhosas. Este canal, braço do rio Macaé, continua sendo utilizado principalmente por crianças da comunidade para diversão nos dias mais quentes.

No Brasil, constitucionalmente, é de competência do poder público local o gerenciamento dos resíduos sólidos produzidos em suas cidades, sendo os vazadouros a céu aberto (lixões) ${ }^{2}$ os mais utilizados. Segundo os dados do IBGE, até o início da década de 1990, esse tipo de destinação, sem preocupações com a contaminação do solo e da água, correspondia a $88 \%$ dos municípios brasileiros. Ainda, no início do século XXI, o vazadouro a céu aberto estava presente em $72 \%$ dos municípios. Somente em 2008 esse número apresentou redução significativa. Porém, o problema ainda é extremamente preocupante, pois aproximadamente $51 \%$ dos municípios apresentam os lixões como destinação final dos resíduos urbanos, incluindo resíduos hospitalares e industriais (IBGE, 2010). Somente em 2010, com a promulgação da Política Nacional dos Resíduos Sólidos, é que o Brasil passa a estabelecer diretrizes relativas à gestão integrada e ao gerenciamento de resíduos sólidos, incluindo as responsabilidades dos geradores e do poder público, e cria os instrumentos econômicos aplicáveis (BRASIL, 2010).

\section{O jornal local e o lixo hospitalar}

Após realizar uma pesquisa nos arquivos de um jornal $^{3}$ de grande circulação da cidade de Macaé, entre os anos de 1980 até 2010, percebemos que a precariedade do sistema de coleta de resíduos da cidade só começou a ser retratada a partir de 1992.

Acredita-se que os temas ambientais começaram a ganhar repercussão na mídia após a realização da Conferência das Nações Unidas sobre o Meio Ambiente e o Desenvolvimento (CNUMAD), Rio-92. Uma notícia de
1993 relata a realização de uma palestra, que apresentava como principal finalidade "educar os funcionários dos setores médicos, ensinando como separar o lixo para evitar contaminação, devendo começar a coleta seletiva no mesmo mês" (O Debate, 1993). No mês seguinte do mesmo ano, foi publicada uma nova matéria indicando que o lixão da cidade continuava recebendo os dejetos hospitalares. A mesma nota orientava para que se colocasse o lixo patológico em sacos plásticos, antes que fosse levado para o latão específico dos detritos hospitalares. E, "no caso do lixo infectante, os técnicos da Secretaria recomendam que o material já utilizado seja colocado em latas de farináceos ou em recipientes plásticos de grande resistência", compondo assim o lixo hospitalar.

No mesmo jornal, os técnicos da Secretaria de Meio Ambiente apontam para o interesse em realizar o lançamento do lixo hospitalar em uma nova área. Entretanto, os técnicos indicam que "no caso específico dos detritos hospitalares, posso adiantar que a área não poderá ser próxima às restingas. Primeiro porque fica muito perto do lençol freático, depois porque o solo é arenoso". Na matéria, o técnico conclui que o projeto da nova área para depósito do lixo hospitalar só deverá ficar pronto no final do ano e "para se trabalhar com este tipo de aterro é necessário um terreno que tenha argila e que seja distante de locais onde possa haver prejuízo da população e do meio ambiente".

A Pesquisa Nacional de Saneamento Básico, realizada em 2008, identificou que 26,8\% (IBGE, 2010) das entidades municipais que faziam o manejo dos resíduos sólidos em suas cidades sabiam da presença de catadores nas unidades de disposição final desses resíduos. Tal atividade foi e é exercida por pessoas que têm como fonte de renda a coleta de materiais recolhidos nos lixões, garantindo, assim, a sobrevivência financeira, inclusive de toda família.

\footnotetext{
${ }^{2}$ Vazadouro a céu aberto (lixão) é o meio mais precário de destinação de resíduos sólidos, com potencial para contaminação do lençol freático. Existem outras formas mais eficientes, como aterro controlado e aterro sanitário, esse último com maiores preocupações em relação a esse tipo de contaminação e à exposição dos seres humanos.

${ }^{3}$ Jornal $O$ Debate. Arquivo gentilmente aberto pelo Museu da cidade de Macaé (Solar dos Mellos). Colaboraram nesta etapa da pesquisa as alunas Anandra de Andrade Machado e Elizabeth de Souza Corrêa (bolsistas do Programa PET - Transversalidade da Temática Água, Curso de Licenciatura em Ciências Biológicas da UFRJ-Macaé Professor Aloísio Teixeira).
} 


\section{Edição das imagens do lixão de São Gonçalo presentes no filme Boca de lixo (1992)}

Boca de lixo é um documentário dirigido pelo cineasta Eduardo Coutinho em 1992 no município de São Gonçalo, retratando o cotidiano de um grupo de catadores de lixo da área. Nesse filme, como define Consuelo Lins, as primeiras imagens se assemelham a um filme de ficção científica, onde "porcos atolam em restos, um cachorro esquelético revolve detritos, um cavalo branco mastiga alguma coisa em meio a uma névoa que paira sobre o lixo". Posteriormente, nos "defrontamos com pessoas com enxadas, pás e ancinhos, que chafurdam no lixo que acaba de ser despejado do caminhão, trazendo para a tela cenas que provocam certo mal-estar no público" (LINS, 2004, p. 87). Para esse estudo, o documentário original foi reeditado/reduzido para um tamanho de três minutos, onde priorizamos a inserção das imagens iniciais do filme, principalmente as cenas que retratavam aspectos como: i) o lixão de São Gonçalo, ii) o cotidiano dos catadores e a chegada dos caminhões para realizar o despejo do lixo, e por fim, iii) a relação de repulsão dos catadores com a câmera.

\section{O diálogo com as imagens: a exibição}

Antes da invenção da escrita, a oralidade era o suporte privilegiado da memória social. A chegada da escrita permitiu registrar os traços desta memória coletiva de maneira mais sistemática e relativamente precisa. A fotografia e o registro fílmico, posteriormente, possibilitam alimentar esta memória social também com elementos audiovisuais (GUARINI, 2002, p. 113). Assim, em junho de 2011, foi realizada uma visita à casa da moradora. Após algumas conversas iniciais, explicamos o motivo da nossa presença naquele dia. Falamos que passaríamos um vídeo e gostaríamos muito que ela o assistisse. Não foi comentado nada em relação às imagens que seriam exibidas, nem onde e quando foram feitas. O vídeo foi exibido em um computador portátil, no quintal da casa da moradora.

Buscamos nesta etapa estabelecer as respostas aos pontos de inserção da edição do vídeo. A ideia de exibir as imagens de outra localidade para a moradora do lixão criou a possibilidade de um novo encontro com o passado, podendo ser recordado ou reinventado, favorecendo, assim, a possibilidade de que a memória, ao invés de ser recuperada ou resgatada, possa ser criada e recriada, a partir dos novos sentidos que a todo tempo se produzem (GONDAR, 2008, p. 5). Nesse sentido, para realizar o estudo em questão, é necessário frisar que realizamos anteriormente algumas entrevistas/conversas com a moradora, que nos relatou previamente sua chegada ao local do antigo lixão, o cotidiano como catadora, as dificuldades enfrentadas durante as jornadas dentro do lixão e a desativação do mesmo. Com isso, esperamos estar desenvolvendo no âmbito dos fenômenos sociais um instrumento generalizado de pesquisa, um instrumento de descoberta, dirigindo no próprio registro do testemunho, como defendido por France (1999).

Para entender o comentário inicial sobre o que ela achou após ter assistido ao vídeo, devemos tentar compreender como as imagens contribuíram para a produção de sentido. As cenas do filme funcionaram não como representações, porém como índices, permitindo que a moradora voltasse à sua própria vivência e de sua família. Nesse tipo de exibição, o que importa é que refletem acontecimentos, emoções, sentimentos que, como tais, não são estereotipados: são relativos à vida da antiga moradora do lixão de Macaé. Essa maneira de produzir sentido foi definida por Odin (2000) como modo privado, uma maneira de leitura de ver um filme voltando-se para sua vivência e/ou a do grupo ao qual se pertence.

Problematizamos neste estudo uma possível influência das imagens em relação ao discurso da catadora, o que Bakhtin (1981, p. 275) chamou de "dialogismo primordial do discurso" e envolve os modos como um falante entra em contato com o outro (as imagens do filme Boca de lixo) e interanimam as enunciações deste. Pensando nisso, buscamos contextualizar as falas da moradora com as três situações que priorizamos na edição do filme Boca de lixo. A conversa com a moradora do antigo lixão foi registrada em vídeo, apresentando, segundo seu relato, diversas semelhanças entre as duas localidades, o lixão de São Gonçalo e o lixão de Macaé, e as mesmas representações visuais entre o cotidiano dos catadores. 


\section{A percepção sobre a vida nos lixões: semelhanças visuais}

As semelhanças visuais entre os lixões são tamanhas que acabaram confundindo a moradora quanto ao local de registro das imagens. A principal semelhança identificada por ela é a presença de animais (urubus, cachorros, porcos):

Esse aí tirou aonde? [comentário sobre o vídeo exibido] Aqui mesmo? Naquela época? [...] Quase que foi a mesma coisa daqui, até lá no fundo lá no canto aquela serrazinha, [referindo-se às montanhas do Rio de Janeiro, semelhantes à Serra de Macaé] dava impressão que filmou de lá pra cá, está parecendo as serras lá. A mesma coisa, os bois, os cachorros, os porcos, a mesma coisa não tem diferença nenhuma. (catadora $\left.{ }^{4}\right)$

Em relação ao cotidiano e à chegada dos caminhões para realizar o despejo do lixo, a moradora apresenta em seu discurso um aspecto de disputa e violência entre os catadores. Em relação às condições de trabalho e de vida, a moradora explica que os caminhões "de firmas" chegavam durante a noite, e por isso, às vezes, o trabalho dos catadores era noturno; havia lixo hospitalar, em um buraco mais afastado e fundo. Os empurrões e as brigas eram frequentes porque "um queria apanhar mais que o outro":

O pessoal catando, o caminhão cheio, estava arriscado o caminhão machucar um ali, a fome era muita de apanhar, um na frente do outro, aqueles empurrões, tinha até briga. O povo brigava, saía na foice, foiçando os outros era horrível, um queria "panhar" mais que o outro, tudo que "panhava" era lucro né! Tudo que pegava dava dinheiro [...] era aquela confusão quando chegava o caminhão, faltava pouco se jogar debaixo do caminhão. (catadora)

Segundo Ferreira e Anjos (2001, p. 69), esses trabalhadores estão expostos em seu processo de trabalho a seis tipos diferentes de riscos ocupacionais: 1) físicos: ruído, vibração, calor, frio, umidade; 2) químicos: gases, névoa, neblina, poeira, substâncias químicas tóxicas; 3 ) mecânicos: atropelamento, quedas, esmagamentos pelo compactador de lixo, fraturas; 4) sobrecarga da função ortomuscular e da coluna vertebral, com consequente comprometimento patológico e adoção de posturas forçadas incômodas; 5) biológicos: contato com agentes biológicos patogênicos (bactérias, fungos, parasitas, vírus), principalmente através de materiais perfurocortantes; 6) sociais: falta de treinamento e condições adequadas de trabalho.

Apesar da precariedade das condições, poder-se-á dizer que a moradora apresenta certo saudosismo da época. Porém, ao mesmo tempo, ela retrata as dificuldades inerentes ao trabalho, existindo, assim, uma contradição entre todos os aspectos negativos narrados por ela (problemas de saúde decorrentes, mau cheiro, feridas frequentes) e a saudade desse período (explicado por ela vagamente ao dizer que "tudo que a gente faz é bom, né?").

Eu achei bom porque já passei por isso, catando as latinhas, catando os cobrinhos, alguma coisa que ainda servia pra comer, já "panhei" muito, já trabalhei muito sobre isso. Hoje sinto uma dorzinha aqui, mais foi daquilo, eu tenho minha unha bloqueada de micose daquilo. Hoje eu não faria mais não. É triste, sabia? Não faço mais não. Mas passando assim eu gosto de parar pra ver, a animação do povo é bom. Tudo que a gente faz é bom, né? Tudo, mesmo que prejudica, mas naquela hora a gente não pensa no que vai acontecer. Mais tarde que pode prejudicar a gente é a saúde, mas por outro lado, naquela hora a gente não sabe de nada, é tudo bom, era uma alegria só, muito bom [comentário sobre as pessoas rindo no filme Boca de Lixo]. Eu tirava cento e cinquenta, quase duzentos reais por semana. Eu comprei boas colchas, panelas. Você sabia que às vezes ali eles tiram mais que uma empregada doméstica de saltinho alto na rua? [...] Era bom. Bom e ruim ao mesmo tempo. Agora não tenho coragem de entrar dentro mais não, não tenho coragem mesmo. Aquilo ali era o fim do mundo. (catadora)

\footnotetext{
${ }^{4}$ Algumas citações dos trechos da entrevista com a catadora passaram por correções na linguagem.
} 
O risco de exposição e contaminação nessas áreas é frequente, principalmente por materiais cortantes. $\mathrm{O}$ problema aumenta quando existe o contato com agentes biológicos patogênicos. Neste caso, a moradora relata a exposição aos riscos descritos:

Cortava na lata, com as latinhas, pisava em cima, se cortava. Eu mesma levei dois cortes enormes, furava a mão. Alguém escorregava, caía e cortava. Saía muito sangue. Aquele sacão de arroz que vinha do restaurante escorregava, caía, rasgava o plástico, caía sentado em cima daquele arroz, molho de tomate, aquelas coisas todas, e agora o fedor. Passava uma pessoa pela gente "vixe Maria" a pessoa saía cuspindo e dizia "que fedor". E agora acabou. (catadora)

Para desativar o Lixão de Águas Maravilhosas, como afirma Ferreira (2011, p. 60), foi registrado por um grupo de 78 moradores do Parque Aeroporto - Macaé, em 12 de abril de 1996, um abaixo-assinado ao Ministério Público do Estado do Rio de Janeiro, com o objetivo de abertura de Ação Pública (PA 004/0 do MPE, 2001) contra a Prefeitura de Macaé. A abertura desse inquérito levou em conta duas principais motivações: a primeira tratava da solicitação de providências quanto à queima do lixo, cuja intensa fumaça provocava danos à saúde. Por conta da fumaça, muitos moradores deram entrada em hospital com problemas respiratórios. A segunda motivação tratava do lançamento de esgoto sanitário diretamente nos canais de drenagem fluvial, o que provocava mau cheiro, além da proliferação de insetos e pequenos roedores, tais como moscas, baratas e ratos, vetores de sintomatologias de viroses e verminoses humanas. Atualmente, alguns catadores de lixo continuam morando na localidade, apesar da desativação do lixão. A entrevistada, assim como outros moradores, cultiva sonhos e medos: o sonho de viver em melhores condições e o medo de serem removidos para outra localidade.

O meu sonho era ter a casinha com tudo dentro, quis fazer uma casa boa, o que não pode fazer aqui. Como que eu sonho com uma casinha, com a varanda bonita, os móveis bonitinhos dentro de casa, fazer um calçadão ali, pros visitantes "passar" o final de semana comigo. Mas não pode, é proibido, tudo aqui é proibido. Não pode fazer mais nada [...] Você não ouviu eles dizendo que vão tirar todo mundo daqui, não? Aqui, minha tristeza é essa. Eu escutei falar, saiu até no jornal, né? Mas eu tô chocada, enquanto durar pra mim é lucro, tô tranquila. (catadora)

Para essa senhora, a ocupação lhe permitiu reproduzir um modo de vida com o qual se identifica, pois pode criar pequenos animais e plantar horta e algumas árvores frutíferas, tal como costumava fazer no campo, onde foi criada, e nos bairros periféricos onde passou a maior parte de sua vida (LEAL; COSTA, 2012). Respondendo à pergunta sobre uma possível remoção, ela argumenta:

De jeito nenhum. Mas a gente não pode com os grandes, né? Essa gente não destrói nada aqui, aqui antigamente era capim e mangue, hoje todo mundo tem um pé de laranja. Eu mesma tenho um pé de laranja, um pé de goiaba, um pé de abacate. Tenho minhas galinhas. Muita gente tem horta. Estamos ajudando, plantando árvores. (catadora)

Em relação à presença de pessoas vivendo na localidade, o Ministério Público entrou com um processo de remoção dessas famílias. A proximidade com o lixo é visível após a retirada de uma fina camada de terra de aproximadamente dez centímetros.

Já em relação à repulsão dos catadores com a câmera e às inúmeras tentativas de se esconder da imprensa, foram também comentadas por ela:

Aqui teve muita filmagem. Teve uma vez que eu me escondi atrás do pé de mato, saí correndo. Depois eu apareci na filmagem correndo pra se esconder, pra não sair né? Eles botavam no jornal $O$ Debate [jornal impresso de grande circulação local] as pessoas carentes daí.

Como afirma Lins (2004, p. 87), a estética da crueldade, o clichê da pobreza brasileira, lembram as imagens que são exibidas na televisão para serem consumidas em forma de espetáculo. A resistência ao filme, à recusa em aparecer e falar é apresentada no documentário de Coutinho. Muitos escondem o rosto, fazem sinal para 
que a equipe vá embora. Os catadores conhecem bem a ideia negativa que os telejornais deles fornecem e não querem reiterá-la (LINS, 2004, p. 88).

\section{Consideração sobre as consequências socioambientais dos lixões}

Foram recolhidos alguns aspectos do lixão localizado em Águas Maravilhosas relacionados: i) à deposição de lixo hospitalar sem tratamento específico; ii) aos riscos de contaminação pelos trabalhadores; iii) à utilização do material encontrado para alimentação; iv) à ausência de cercas; v) à presença de animais; vi) à proximidade com águas superficiais; vii) à proximidade de moradias; e viii) à ausência de coleta seletiva no município. A identificação desses pontos foi analisada por outros autores (FRANÇA; RUARO, 2009) em trabalho semelhante em lixões de Santa Catarina.

No quesito proximidade com águas superficiais, a contaminação da água subterrânea e superficial por chorume é uma das maiores preocupações com relação aos lixões desativados (FRANÇA; RUARO, 2009, p. 2195). Nesse caso, a moradora identificou que a instalação do lixão ocorreu a menos de dez metros de distância do canal. É importante frisar que esse canal ainda apresenta ligação com o rio Macaé, o principal rio da cidade. Outro fator crítico observado pelos pesquisadores está relacionado com a coleta e tratamento de chorume e do biogás, sendo um dos principais problemas de contaminação ambiental pelos lixões desativados. Em Águas Maravilhosas, este tipo de coleta é ausente, ou seja, a verificação in loco permitiu detectar que não existe nenhum tipo de equipamento para a queima do biogás e o tratamento do chorume.

A presença de pessoas nos lixões é outra grande preocupação, pois a contaminação acontece de formas direta e indireta, afetando gravemente a saúde dessas pessoas. Da mesma forma, os animais, alimentando-se dos detritos orgânicos contaminados, se tornam transmissores de doenças. O problema se agrava quando esses animais são utilizados na alimentação de pessoas (FRANÇA; RUARO, 2009, p. 2194). Neste caso, assim como em São Gonçalo, o lixão de Macaé também apresentava pessoas e animais e a própria moradora afirma ter se cortado com latas abertas e vidros quebrados, conforme apresentado acima. Em relação à distância de moradias, a ex-catadora relatou que muitas pessoas foram morar nas proximidades do lixão para sustento e alimentação após a instalação do mesmo. O lixão foi, portanto, um fator de aglomeração urbana.

Atualmente, Macaé deposita os seus resíduos sólidos urbanos em dois aterros sanitários e, segundo as autoridades do governo, em ambas não existem pessoas trabalhando como catadores. Porém, o município ainda não possui coleta seletiva e os trabalhadores do lixo podem estar espalhados pela cidade. A atuação de catadores na segregação do lixo para alimentação, seja nas ruas ou nos vazadouros, é o ponto mais problemático da relação do lixo com a população "invisível” e marginalizada da sociedade. Quanto ao tipo de cobertura, observou-se que o lixão de Macaé recebeu uma fina camada de terra, de menos de vinte centímetros, conforme descrito neste artigo. Essa cobertura não evita os problemas ambientais e de saúde gerados pela decomposição dos resíduos.

Apesar de Macaé ter avançado em números como crescimento econômico, oferta de empregos e royalties, parece que não foram dadas atenções às formas de destinação dos resíduos sólidos urbanos em décadas passadas, gerando problemas atuais de contaminação ambiental e exclusão social (HERCULANO; CORREA, 2010, p. 172). Entretanto, o problema de invasão das áreas de lixão não é único e exclusivo de Macaé, pois vêm sendo relatados diversos casos parecidos na mídia (o mais famoso é o caso do Morro do Bumba, em Niterói).

Por meio de conversa informal com a moradora, identificamos que o conhecimento adquirido por ela ao longo dos anos contribuiu para que tivéssemos uma melhor compreensão dos problemas, dificuldades e do cotidiano dos catadores e da própria comunidade Águas Maravilhosas. Dificilmente sem os depoimentos dessa moradora poderíamos identificar alguns pontos abordados aqui. Asseguramos a privacidade, o sigilo e o anonimato dela, conforme preconizado pela resolução CNS 196/96, que garante a não utilização das informações em prejuízo das pessoas e/ou comunidades.

Em consideração às memórias da catadora, acreditamos na importância da narrativa que conta as mudanças ambientais ocorridas em uma região e, mais do que isso, o que foi vivido pela própria narradora. Ou seja, aqueles 
que sofrem as consequências de decisões das quais não participaram, que vão se adaptando, se adequando às mudanças e buscando sua sobrevivência à medida que o próprio ambiente procura sobreviver.

\section{Considerações finais}

Neste artigo, buscamos compor um cenário sobre o principal lixão de Macaé, em funcionamento até 2000. Acreditamos que a compreensão sobre o histórico de uso dessa área contribui para o entendimento das consequências atuais relacionadas às possíveis contaminações químicas no solo e na água. Assim, as impressões e memórias de uma ex-catadora e moradora foram cruciais para esse entendimento. Entretanto, é necessário reforçar que esse ambiente carece de outros estudos, que possibilitarão o amplo entendimento da situação socioambiental de Águas Maravilhosas, como exemplo análises químicas de metano e contaminantes físico-químicos do líquido lixiviado, principalmente metais pesados (Cd, Pb, Cr, Hg, Ni e Zn). Não encontramos

\section{Referências}

BAKHTIN, M. The dialogic imagination: four essays by M. M. Bakhtin. Editado por Michael Holquist. Traduzido por Caryl Emerson and Michael Holquist. Austin: University of Texas Press, 1981. 2003. p. 410.

Estética da criação verbal. São Paulo: Martins Fontes,

BRASIL. Lei n. 12.305, de 02 de agosto de 2010. Institui a Política Nacional de Resíduos Sólidos; altera a Lei n. 9.605, de 12 de fevereiro de 1998, e dá outras providências. Diário Oficial da União, Brasília, n. 147, p. 3, 03 de agosto de 2010.

BENJAMIN, W. O narrador. In: . Magia e técnica, arte e política. São Paulo: Brasiliense, 1994.

BERNARD, H. R. Research methods in cultural anthropology. Newbury Park: Sage Publications, 1988. 520 p.

BOSI, E. Memória e sociedade: lembranças de velhos. São Paulo: T. A. Queiroz, 1979. registros na literatura, nas universidades e centros de pesquisas locais sobre a realização deste tipo de análise no local de estudo. O cotidiano e as condições de trabalho relatados pela catadora do lixão de Macaé retratam exemplos de desigualdade na exposição a riscos e danos ambientais que perduram até o momento em diversos municípios do Brasil.

Esperamos que o resgate histórico da descaracterização de um ambiente, com relevâncias ambientais, históricas e sociais, relatado por uma pessoa que viu e vivenciou todas as etapas desta ausência de planejamentos e estudos técnicos, possa contribuir para futuras intervenções neste local.

O problema da destinação final dos resíduos sólidos na cidade de Macaé ainda é tema dos debates no plenário da Câmara dos Vereadores, como o ocorrido em novembro de 2012. Na ocasião, os vereadores discursaram sobre as dificuldades em controlar o descarte irregular do lixo nas ruas, a ausência de políticas públicas eficientes para solucionar o problema do lixo na cidade e a falta de investimentos em projetos sociais para geração de emprego e renda.
COMISSÃO NACIONAL DE ÉTICA EM PESQUISA (BR). A ética nas ciências humanas. Cad. Ética Pesq., v. 1, n. 1, p. 34-46, jul. 2000.

CORRÊA, G. G.; MALHÃO, T. A.; ASMUS, C. I. R. F.; COELI, C. M. Perfil socioeconômico das populações expostas a resíduos da exploração de petróleo. Revista Brasileira Epidemiol., v. 14, n. 3, p. 372-385, set. 2011.

FERREIRA, J. A.; ANJOS, L. A. dos. Aspectos de saúde coletiva e ocupacional associados à gestão de resíduos sólidos municipais. Cad. Saúde Pública, v. 17, n. 3, p. 689-696, maio-jun. 2001.

FERREIRA, M. A. V. A. Injustiça ambiental associada à disposição final de resíduos sólido urbanos em Macaé/RJ: do vazadouro em Águas Maravilhosas ao aterro sanitário na BR-101. 60 p. Dissertação (Mestrado) - Instituto Federal de Educação, Ciência e Tecnologia. 2011.

FRANÇA, R. G.; RUARO, É. C. R.. Diagnóstico da disposição final dos resíduos sólidos urbanos na região da Associação dos 
Municípios do Alto Irani (AMAI), Santa Catarina. Ciência \& Saúde Coletiva, Rio de Janeiro, v. 14, n. 6, 2009.

FRANCE, C. Cinema e Antropologia. Campinas, SP: Ed. Unicamp, 1999.

FROCHTENGARTEN, F. A memória oral no mundo contemporâneo. Estud. Av., v. 19, n. 55, p. 367-376, 2005. [on-line]

GIATTI, L. L.; NEVES, N. L. S.; SARAIVA, G. N. de M.; TOLEDO, R. F. de. Exposição à água contaminada: percepções e práticas em um bairro de Manaus, Brasil. Rev. Panam. Salud Publica, v. 28, n. 5, p. 337-343, 2010.

GONDAR, J. Memória individual, memória coletiva, memória social. Morpheus - Revista Eletrônica em Ciências Humanas, ano 8, n. 13, 2008.

GUARINI, C. Memoria social e imagen. Cuad. Antropol. Soc., n. 15 , p. 113,2002 . [on-line]

HALBWACHS, M. (1877-1945). A memória coletiva. São Paulo: Vértice, 1990. p. 26.

HERCULANO, S.; CORREA, H. Impactos sociais, ambientais e urbanos das atividades petroliferas: o caso de Macaé. Niterói: UFF, 2010.

IBGE. Instituto Brasileiro de Geografia e Estatística. Pesquisa Nacional de Saneamento Básico, 2008. Rio de Janeiro, 2010.

. Censo demográfico 2010. Rio de Janeiro: IBGE, 2010.

LEAL, G. F.; COSTA, R. N. Sentidos da moradia e do lugar: estudo de caso de uma comunidade face à possibilidade de remoção. Boletim do Observatório Ambiental Alberto Ribeiro Lamego, Programa de Mestrado em Engenharia Ambiental do
Instituto Federal de Educação, Ciência e Tecnologia Fluminense (IFF), v. 6, p. 43, 2012.

LINS, C.. O documentário de Eduardo Coutinho: televisão, cinema e vídeo. Rio de Janeiro: Jorge Zahar Editor. 2004.

O DEBATE, Diário de Macaé. Lixo hospitalar terá sistema de coleta seletiva em Macaé. 22 de março de 1993a.

. Coleta seletiva de lixo hospitalar deverá começar dia 7 em Macaé. 02 de abril de 1993b.

ODIN, R. A questão do público: uma abordagem semiopragmática. Título original: "La question du public: approche sémiopragmatique”, em Réseaux, n. 99, p 49-72, 2000. Tradução de Eric Roland René Heneault.

POSTALI, F. S.; NISHIJIMA, M. Distribuição das rendas do petróleo e indicadores de desenvolvimento municipal no Brasil nos anos 2000. Est. Econ., São Paulo, v. 41, n. 2, p. 463-485, 2011.

SEVÁ FILHO, A. O. O Estado do Rio de Janeiro, capital dos problemas ambientais e sociais da indústria petrolífera - os casos do litoral Norte Fluminense e da Baía da Guanabara. FASE-RJ. Sindipetro Caxias, 2012. [no prelo]

SHIRAIWA, S. et al. Estudos geofísicos integrados no lixão de Cuiabá, MT, Brasil: resultados preliminares. Rev. Bras. Geof., São Paulo, v. 20, n. 3, p. 181-186, 2002. [on-line]

SILVA, J. E. da et al. Aplicação de ensaios elétricos e eletromagnéticos em problema de poluição ambiental. Rev. Bras. Geof., São Paulo, v. 20, n. 3, p. 193-198, set.-dez. 2002. [on-line]

WERTSCH, J. V. Text and dialogism in the study of collective memory. Educ. Pesq., v. 36, n. esp., p. 123-132, 2010. [on-line]

Recebido em 6 de agosto de 2012. Aceito em 20 de março de 2013. Publicado em junho de 2013. 